Letter to editor

\title{
Use of Aloe vera (L.) Burm.f. in the treatment of piles
}

\section{Gammel Ahmed Baghaffar}

\author{
Department of Chemistry, Faculty of Science, Hadramout University of Science and Technology, \\ Mukalla, Yemen
}

*Corresponding Author: djamil_12@yahoo.com

[Accepted: 25 February 2017]

[Cite as: Baghaffar GA (2017) Use of Aloe vera (L.) Burm.f. in the treatment of piles. Tropical Plant Research 4(1): 103]

Aloe vera (L.) Burm.f. is widely cultivated throughout the globe for their various medicinal properties. The native range of the species is doubtful, but it is assumed that the species may be native of Socotra (Yemen), Somalia and Sudan (Treutlein et al. 2003). The plant has been used by the people of a number of civilisations i.e. Greece, Egypt, India, Mexico, China and Japan for different purposes (Morton 1961, Crosswhite \& Crosswhite 1984, Marshall 1990, Mehra et al. 2014).

The use of Aloe extract orally in the treatment of inflammation (Reynoldsa \& Dweckb 1999), diabetic wounds (Chithra et al. 1998b), high cholesterol (Dixit \& Joshi 1983) and other gastrointestinal difficulties (Bland 1985) have already been described.

In the summer of 2004, I had vigorous piles. I used drugs under the guidance of physician for a month. After not getting any significant benefit, my doctor decided to operate the piles. In the meanwhile, one of my friends Mr. Abdunnaser Albataty, advised me an ethnic method for treating it. As per his instruction, I prepared a dilute solution of Aloe (i.e. $1 \mathrm{~g} / 250 \mathrm{ml}$ water). Now, filtrated the impurities to obtain pure solution. In the morning, before breakfast, $30 \mathrm{ml}$ of this purified solution with 3-5 drops sesame oil was taken. This was repeated for one month. After one month continuous use of this method, I felt comfortable. I shared this method among the people and also broadcast this method with the help of a radio programme. Number of people had been medicated by this method. That's why, here I am informing you this method of piles treatment.

\section{DECLARATION}

These are the author's own views, experience and observation. Journal is not responsible for any kind of discomfort to anyone.

\section{REFERENCES}

Bland J (1985) Effect of orally consumed Aloe vera juice on gastrointestinal function in normal humans. Preventive Medicine 14: 152-154.

Chithra P, Sajithial G.B \& Chandrakasan G (1998) Influence of Aloe vera on the healing of dermal wounds in diabetic rats. Journal of Ethnopharmacology 59: 195-201.

Dixit VP \& Joshi S (1983) Effect of Aloe barbedensis and clofibrate on serum lipids in triton induced hyperlipidaemia in Presbytis monkeys. Indian Journal of Medical Research 78: 417-421.

Crosswhite FS \& Crosswhite CD (1984) Aloe vera, plant symbolism and the threshing floor. Desert Plants 6 : 43-50.

Morton JF (1961) Folk uses and commercial exploitation of Aloe leaf pulp. Economic Botany 15: 311-319.

Marshall JM (1990) Aloe vera gel: what is the evidence? Pharmaceutical Journal 244: 360-362.

Mehra A, Bajpai O \& Joshi H (2014) Diversity, utilization and sacred values of Ethno-medicinal plants of Kumaun Himalaya. Tropical Plant Research 1(3): 80-86.

Reynoldsa T \& Dweckb AC (1999) Aloe vera leaf gel: a review update. Journal of Ethnopharmacology 68 (13): 3-37.

Treutlein J, Smith GF, van Wyk BE \& Wink W (2003) Phylogenetic relationships in Asphodelaceae (Alooideae) inferred from chloroplast DNA sequences (rbcl, matK) and from genomic finger-printing (ISSR)". Taxon 52(2): 193. 